\title{
TREATMENT OUTCOME OF TWO SHORT IMPLANT RETAINED MANDIBULAR OVERDENTURE IN COMBINATION WITH PHOTOBIOMODULATION
}

\author{
Sara M. Zayed ${ }^{1 *} M s c$, Marwa G. Noureldin² $P h D$, Ahmad M. Alshimy ${ }^{3} p h D$, \\ Ahmed A. Abdel Hakim ${ }^{4} P h D$
}

\begin{abstract}
:
INTRODUCTION: Restoration of atrophic mandible with short implants has revolutionized dentistry. Computer guided implant surgery has been verified to be an established minimally invasive treatment and Photobiomodulation (PBM) has proven to be an effective modality in accelerating post-surgical healing and implant osseointegration.

AIM OF THE STUDY: To evaluate the clinical and radiographic outcomes of mandibular overdentures retained by two short implants in combination with two different doses of PBM.

MATERIALS AND METHODS: Six completely edentulous patients received two short dental implants (4mm diameter and 7mm length) in canine area. Short implants were inserted via CAD/CAM surgical guide. Patients received 5 PBM sessions immediately after surgery and every 48 hours. Group A ( $n=6$ ) right side implants received dose of $2.4 \mathrm{~J} / \mathrm{cm} 2$, and group B ( $\mathrm{n}=6$ ) left side implants received dose $4.8 \mathrm{~J} / \mathrm{cm} 2$. Implants were loaded after 3 months. Each implant was evaluated at time of initial prosthetic loading and 6 months later for peri-implant probing depth (PIPD), modified gingival index (MGI), and vertical bone loss. Implant stability was assessed at the time of surgery and 6 months after loading.

RESULTS: The findings of this study indicate that after 6 months, two short implant retained overdentures showed no biological nor mechanical complications. A minor but significant increase $(\mathrm{P}<0.05)$ was observed in the PIPD after 6 months in both groups. The MGI values were very low. Radiographic evaluation revealed minimal insignificant marginal bone loss $(\mathrm{P}>0.05) 0.51+30$, 0.38+28 for group A and group B respectively. Implant stability values for group A were almost maintained and there was a slight increase in group B after 6 months. Insignificantly better results were reported with group B.

CONCLUSION: Two short implant retained overdenture can be a viable option for atrophic mandibles and PBM dose of $4.8 \mathrm{~J} / \mathrm{cm} 2 \mathrm{has}$ a potential positive influence on healing and implants osseointegration.

KEYWORDS: Atrophic mandible, short dental implant; guided implant surgery, photobiomodulation.
\end{abstract}

1. Assistant Lecturer of Prosthodontics, Faculty of Dentistry, Alexandria University, Egypt.

2. Lecturer of Oral Surgery, Faculty of Dentistry, Alexandria University, Egypt.

3,4 Professor of Prosthodontics, Faculty of Dentistry, Alexandria University, Egypt

*Corresponding author:

Email: $\underline{\text { dr_sara_23@hotmail.com }}$

\section{INTRODUCTION}

Edentulous patients frequently suffer profound problems with their complete mandibular dentures. The main complaints include, but not limited to; lack of retention and stability of mandibular dentures, coupled with a dramatic reduction in the masticatory efficiency (1). Attributable to the diminished surface area and the unreliable peripheral seal, a mandibular denture must rely on the proper boarders' extension while evading overextension that yields denture dislodgement by the muscle attachments while functioning. This alone is an elusive balance to achieve. By combining the problems of poor bone height on the mandibular ridge with large tongues or poor lateral throat form, the mandibular denture becomes the most problematic prosthesis to attain satisfactory retention for the patient during function.

A current well-founded treatment option is to insert endosteal implants in the mandible to retain an overdenture $(2,3)$. The substantial evolution of the implant overdentures has significantly enhanced the clinical performance of complete dentures in aspects of denture support, retention, stability as well as chewing efficiency $(4,5)$. Nonetheless, severe forms of ridge resorption are regarded to be beyond the scope of implant prosthodontics. Unless adequate bone height is evident, bone augmentation and grafting are considered compulsory prerequisites (6). Seeking alternatives to the time-consuming and risk associated augmentation procedures became a motivating topic for researchers. The reliance on short implants amplified after the initial evidence suggesting that the improved predictability of short dental implants has been supported by the various biomechanical studies (7), advocating that the most crucially involved part in load-bearing is the crestal portion of the implant body. Hence, implant length may not be a cardinal factor for implant failure (7-10). Moreover, this protocol is in line with contemporary inclination towards minimally invasive techniques. Furthermore, digital implantology with computer guided implant surgery propose a wise modality to satisfy the enormously rising demands and can be viewed as one of the most important innovation drivers in the dental arena and its pace keeps rising (11-13). However, there's no consensus on the number of short implants required to retain mandibular overdenture. 
Zayed et al.

Photobiomodulation (PBM) has demonstrated to be a potentially effective modality in accelerating the healing process and enhancing bone formation (14-18). Given the successful application of non-ablative lasers to boost formation of new bone, this promising treatment modality was employed by researchers to accelerate healing of peri-implant bone in attempt to shorten the healing time before definitive prosthesis insertion. The positive outcomes of PBM have provided a modality to accelerate osseointegration. Thus, PBM has become a promising adjuvant therapy in cases of rehabilitation including implant prosthodontics $(18,19)$. Nevertheless, there is no standardized protocol nor dose for the application of PBM to enhance dental implants osseointegration (20). Consequently, this study aims to evaluate and compare the outcomes in terms of; implant stability, peri-implant hard and soft tissues change of two short dental implants retained mandibular overdentures in combination two different doses of PBM.

The null hypothesis of this study was that for a mandibular overdenture retained by two short implants, right side implants irradiated with PBM for 2 minutes and left side implants irradiated for 4 minutes will not reveal difference in the clinical and radiographic parameters assessed.

\section{MATERIALS AND METHODS}

The study protocol was approved by research ethics committee of Faculty of Dentistry, Alexandria University, Egypt, to ensure the protection of the participants and it is registered in www.clinicalTrials.gov (ID: NCT03540316).

\section{Patient Selection}

Six completely edentulous male patients were selected from the outpatient clinic, Department of Prosthodontics, Faculty of Dentistry, Alexandria University, Alexandria, Egypt. Their mean age is 55 years (range 45 to 65 years), they presented with persistent retention problems with their conventional mandibular complete dentures due to atrophic mandibular ridge. The selected patients were included if they were free from systemic disorders and have healthy mucosa as well as class I ridge relation. Patients were excluded if they were smokers, diabetic or had osteoporosis, or undergone radiotherapy to the head and neck region. All patients signed an informed consent form.

\section{Surgical and Prosthetic Procedures}

All patients received new maxillary and mandibular complete dentures. Patients were given instructions to follow strict oral hygiene measures and denture care. A preoperative panoramic radiograph and cone beam computed tomography (CBCT) were done for every patient to locate important anatomical landmarks and evaluate the potential implant placement sites.

Dual scan was performed and the CAD/CAM customized surgical guide was then fabricated by $3 \mathrm{D}$ printing (Form2, Formlabs, Somerville, MA, USA) using the scanned radiographic template as reference (21). It was employed to guarantee the implants were placed in a predictable, and accurate parallel manner. Antibiotic (1gm of amoxicillin and clavulanic acid orally/ 12 hours) was prescribed one day pre-operatively and continued for six
Two Short Implant Retained Mandibular Overdenture and PBM days post-operatively. Also, $0.12 \%$ chlorhexidine rinse was prescribed two days pre-operatively, it was used twice daily and continued post-operatively $(22,23)$.

Each patient received two short dental implants (4mm diameter and 7mm length; $5.5 \mathrm{~mm}$ intra-bony, 1.5 mm soft tissue, Dentium, Korea) bilaterally in the canine region. Implants were placed under local anaesthesia via a flapless implant surgery aided by the customized surgical guide, which was stabilized by fixation pins guided by occlusal index to reproduce the virtually planned position. While the surgical guide in place and according to the manufacturer's instructions, as well as, the calibrated sequential drilling protocol, the osteotomy site was prepared using the appropriate pre-planned drills sequence according to the 3D planning and guided surgery report provided (21). All implants were placed by the same clinician.

After implants were placed, the surgical guide was removed and the implants' primary stability was assessed by Osstell ISQ ${ }^{\mathrm{TM}}$ instrument (Integration diagnostics Ltd., Sweden) finally cover screws were fastened on the implants (Fig 1). Patients were instructed to complete the prescribed medications and given detailed instructions with regard to oral hygiene measures. To avoid loading of the surgical area, patients were not allowed to wear the mandibular denture for 2 weeks postsurgically, and later the denture was adjusted to accommodate the cover screws and implants.

The implants remained unloaded for three months. Then, the second prosthetic phase started in which implants were exposed and cover screws removed under local anaesthesia by the same investigator and selfaligning positioner abutments of $2 \mathrm{~mm}$ trans-mucosal cuff height were screwed in to the implants. Positioner abutments (Superline, Dentium Co. Ltd., Korea) were then attached to the dentures by matching self-aligning positioner attachments (Superline, Dentium Co. Ltd., Korea) by means of a chair-side processing method, direct pickup of the female housings in the fitting surface of the mandibular denture was performed.

\section{Laser Irradiation (PBM) Protocol}

PBM by laser irradiation started immediately postsurgerical and repeated every two days (48 hours), each patient underwent 5 sessions in total. They received PBM by a semi-conductor diode laser (Sirolaser blue, Sirona, Germany). The wavelength used was; $660 \mathrm{~nm} \pm 5$, an output power of $25 \mathrm{~mW}$ (24), the operating mode was continuous wave $(\mathrm{CW})$.

At this stage, split mouth design was adopted and patients were blinded to the PBM doses.; group A was the right-side implant received PBM for 120 seconds and group B; left side implant (same patient) and received PBM for 240 seconds. Multiplying the laser output power in watts by the time of exposure in seconds equals the produced energy, thus energy per session $=0.25 \mathrm{~W} \times 120 \mathrm{~s}$ $=3 \mathrm{~J}$ for group $\mathrm{A}$ and $0.25 \mathrm{~W} \times 240 \mathrm{~s}=6 \mathrm{~J}$ for group $\mathrm{B}$. Laser spot size (size of irradiated area) was $8 \mathrm{~mm}$, resulting in a calculated energy density (Dose) of: $2.4 \mathrm{~J} / \mathrm{cm}^{2}$ for group $\mathrm{A}$ and $4.8 \mathrm{~J} / \mathrm{cm}^{2}$ for group $\mathrm{B}$. Implants were irradiated intraorally, orthoradially to the implant's longitudinal axis in non-contact mode by a hand held probe (multi-tip) 1-2 mm away from the implants (Fig. 2). 
Zayed et al.

Biosafety standards for infection control and waste disposal were strictly implemented throughout all therapy sessions.

\section{Evaluation Phase}

The clinical outcome of treatment of resorbed mandibular ridge by using short implants retained overdenture and PBM was evaluated by blinded operator, in terms of; implant stability, peri-implant bone and soft tissue changes.

\section{i. Clinical evaluation:}

\section{a. Peri-implant Probing Depth (PIPD):}

It is the distance measured between the marginal border of the gingival margin and the most apically probeable part, in millimetres (mm). PIPD was measured at 4 sites around each implant (mesially, distally, labially/buccally, lingually). Then, the mean record for every implant was calculated. It was measured at time of prosthetic loading (baseline) and six months after implant placement (25).

\section{b. Modified Gingival Index (MGI):}

To qualify the peri-implant inflammation, modified gingival index (modified Löe and Silness index) was performed. It was measured at 4 sites around each implant (mesially, distally, labially/ buccaly, lingually), then, the mean record was calculated for each implant. MGI was evaluated at time of prosthetic loading (baseline) and 6 months after implant insertion (26). The scoring criteria were as follows:

Score 0: normal peri-implant mucosa;

Score 1: mild inflammation, slight change in colour, slight oedema;

Score 2: moderate inflammation, redness, oedema, and glazing;

Score 3: severe inflammation, marked redness, oedema, and ulceration.

\section{c. Implant Stability Test:}

To assess the process of osseointegration, implant stability was measured by resonance frequency analysis (RFA). It was carried out at the time of implant insertion and six months later. RFA was done using the Osstell ISQ $^{\mathrm{TM}}$ instrument (Integration diagnostics Ltd., Sweden); a non-invasive objective system that doesn't jeopardize the healing process. Measurements were done for buccal/labial, mesial and distal sites. Each measurement was repeated till the same value was recorded twice, which was accepted as the authentic value. Then, the mean Implant stability quotient (ISQ) values for each implant were calculated $(27,28)$.

\section{ii. Radiographic Evaluation:}

It was carried out to detect peri-implant vertical marginal bone loss over time. Standardised digital periapical radiographs via paralleling technique with sensor holder was performed. Peri-implant vertical alveolar bone loss was measured (in $\mathrm{mm}$ ) using Sidexis 4 software (Version 4.1, Dentsply Sirona , GmbH , Germany). In this study, the baseline radiographs were taken at the time of prosthetic loading when transmucosal part pierces the mucosal tissues. Reference line for bone level evaluation was the threaded intra-bony boarder of the implant (smooth/rough interface of the implant which is located $1.5 \mathrm{~mm}$ apical from the implant shoulder). After six months, measurements were done at the mesial and distal
Two Short Implant Retained Mandibular Overdenture and PBM surface of each implant, then the mean values were calculated(29).

\section{Statistical Analysis}

Data were fed to the computer and analysed by SPSS ${ }^{\circledR 20.0}$ software (SPSS Inc., Chicago, IL, USA). Quantitative data was described by mean and standard deviation. For normally distributed data comparison between two independent populations was done using independent t-test while for comparison in the same group paired student t-test was used. Significance test results are quoted as two tailed probabilities. significance of the obtained results was judged at the $5 \%$ level. Differences were considered to be statistically significant at $\mathrm{P}<0.05$.

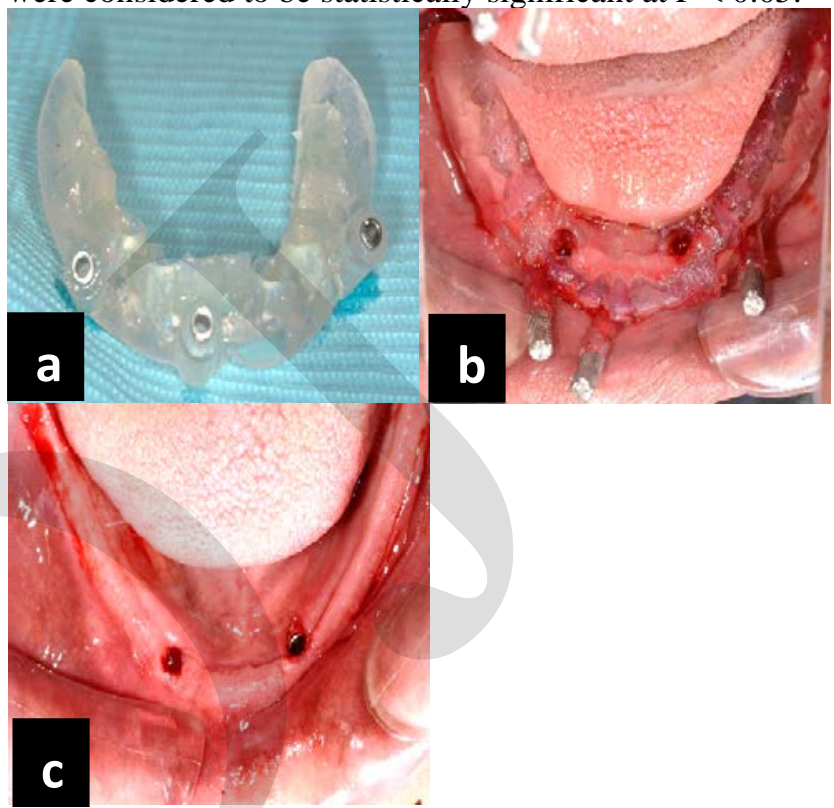

Figure 1: a) 3D printed surgical guide b) implants inserted with surgical guide in place c) surgical guide removed and cover screws tightened.

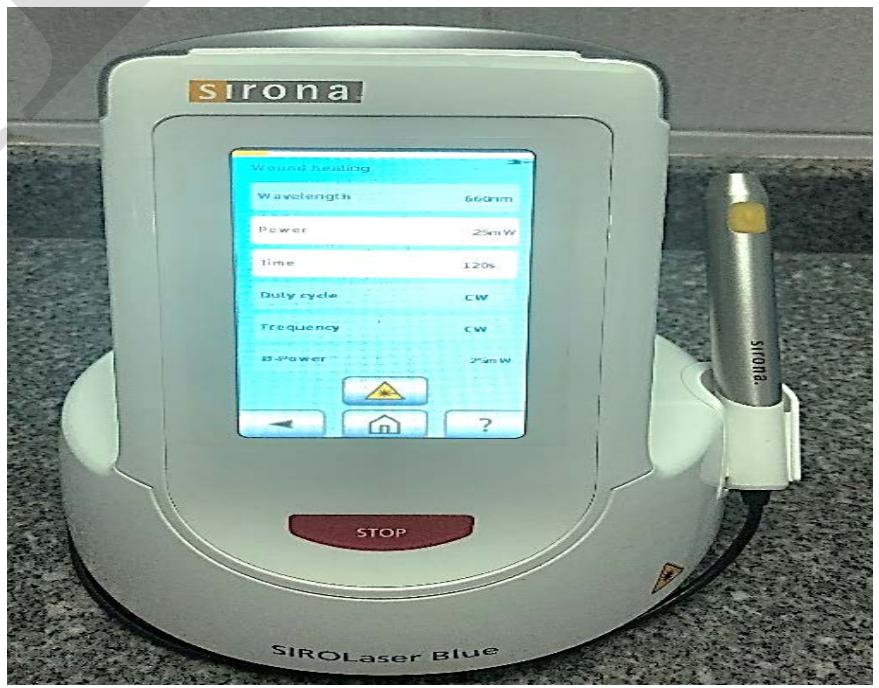

Figure 2: a) Sirolaser blue device b) Laser multi-tip 1-2 mm from the implants

\section{RESULTS}

All the patients enrolled in the present study received the intended treatment and successfully completed the study protocol. All the placed short dental implants were clinically stable and free of symptoms; radiographically no pathological marginal bone loss was 
Zayed et al.

observed around the implants. The short dental implants' success rate was $100 \%$. All implants were followed-up and considered for the analysis. The implants and related prostheses were stable, and no complications were observed during the follow-up period.

\section{Clinical Parameters}

\section{a. Peri-implant Probing Depth:}

All patients maintained meticulous good oral hygiene throughout the study period. The mean periimplant probing depth at the baseline was 1.06+0.27 and $0.94+0.21$ for group A and B respectively. After 6 months follow up these values slightly increased to be $1.98+0.5$ for group A and $1.73+0.36$ for group $\mathrm{B}$. Thus, a minor but significant change $(\mathrm{P}<0.05)$ in probing depths during the evaluation period was observed after 6 months of prosthesis loading (Table 1). Nevertheless, there was no significant difference between both groups after 6 months.

\section{b. Modified Gingival Index}

The mean MGI values for both groups at baseline and after 6 months are displayed in (Table 2). At the time of prosthesis loading, no signs of inflammation were reported. After 6 months the mean scores on the modified gingival index were very low at the evaluation period. No significant differences between the groups were observed.

\section{c. Implant Stability Measurement}

The mean (ISQ) values for group A and B, at time of surgery (baseline) and after 6 months are shown in (Table 3). The results of t-test showed that the mean difference in ISQ at baseline and after 6 months $(P=0.13$, $\mathrm{P}=0.15$ respectively) was not significant between both groups. The primary ISQ values were almost maintained in group A during the study period and there was a minor increase in these values for group $B$. However, no significant differences were demonstrated in the ISQ values between both groups during the examination period.

\section{Radiographic parameters}

Digital peri-apical radiographs showed normal peri-implant bone structure with no signs of continuous radiolucency around the implant threads during the observation period. At the start of prosthetic loading after the healing period and bone remodelling, bone levels were stable at the reference line threaded intra-bony boarder of the implant (smooth/rough interface of the implant). The average bone loss after 6 months of loading was $0.51+$ 0.30 and $0.37+0.28 \mathrm{~mm}$ in groups $\mathrm{A}$ and $\mathrm{B}$, respectively. No significant differences $(\mathrm{P}>0.05)$ in marginal bone loss were observed between both groups. Changes in the marginal bone levels are shown in (Table 4).

Table (1): Comparison between the two studied groups regarding probing depth at base line and after 6 months.

\begin{tabular}{|l|l|l|l|}
\hline $\begin{array}{l}\text { Probing } \\
\text { depth }\end{array}$ & Group A & Group B & $\begin{array}{l}\text { t-test 1 } \\
\text { P value }\end{array}$ \\
\hline At base line & & & \\
Range & $0.75-1.50$ & $0.63-1.13$ & \\
Mean & 1.06 & 0.94 & 1.44 \\
S.D. & 0.27 & 0.21 & 0.19 N.S. \\
\hline After 6 & & & \\
months & & & \\
Range & $1.25-2.63$ & $1.25-2.25$ & 1.48 \\
Mean & 1.98 & 1.73 & 0.17 N.S. \\
S.D. & 0.50 & 0.36 & \\
\hline t-test 2 & 4.25 & 6.98 & \\
P value & $0.001^{*}$ & $0.0005^{*}$ & \\
\hline
\end{tabular}

Two Short Implant Retained Mandibular Overdenture and PBM t-test 1: Comparison between group $\mathrm{A}$ and $\mathrm{B}$ at the same time. t-test 2: Comparison between base line and after 6 months in the same group

$\mathrm{p}$ is significant if $\leq 0.05 *$ Significant at level 0.05 N.S. not significant

Table (2): Comparison between the two studied groups regarding gingival index 6 months.

\begin{tabular}{|l|l|l|l||}
\hline $\begin{array}{l}\text { Gingival index } \\
\text { 6 months }\end{array}$ & Group A & Group B & $\begin{array}{l}\text { t-test } \\
\text { P value }\end{array}$ \\
\hline Range & $0.25-2.00$ & $0.00-1.25$ & \\
Mean & 0.96 & 0.54 & 1.54 \\
S.D. & 0.62 & 0.51 & 0.12 N.S. \\
\hline
\end{tabular}

p is significant if $\leq 0.05$

N.S. not significant

Table (3): Comparison between the two studied groups regarding gingival index after 6 months

\begin{tabular}{||l|l|l|l||}
\hline Implant stability & Group A & Group B & $\begin{array}{l}\text { t-test } 1 \\
\text { P value }\end{array}$ \\
\hline At base line & $63.33-$ & & \\
Range & 78.33 & $54.67-73.67$ & \\
Mean & 69.89 & 67.17 & 1.86 \\
S.D. & 6.27 & 7.53 & 0.13 N.S. \\
\hline After 6 months & $64.33-$ & & \\
Range & 74.00 & $62.67-75.00$ & \\
Mean & 69.11 & 72.06 & 1.82 \\
S.D. & 5.46 & 5.71 & 0.15 N.S. \\
\hline t-test 2 & 0.98 & & \\
P value & 0.315 & 1.69 & \\
& N.S. & 0.132 N.S. & \\
\hline
\end{tabular}

t-test 1: Comparison between group $\mathrm{A}$ and $\mathrm{B}$ at the same time. t-test 2: Comparison between base line and after 6 months in the same group

$\mathrm{p}$ is significant if $\leq 0.05$

N.S. not significant

Table (4): Comparison between the two studied groups regarding radiographic evaluation after 6 months from the reference point.

\begin{tabular}{|l|l|l|l||}
\hline & Group A & Group B & $\begin{array}{l}\text { t-test } \\
\text { P value }\end{array}$ \\
\hline Range & $0.10-0.80$ & $0.10-0.70$ & \\
Mean & 0.52 & 0.43 & 1.09 \\
S.D. & 0.28 & 0.25 & 0.20 N.S. \\
\hline
\end{tabular}

$\mathrm{p}$ is significant if $\leq 0.05$

N.S. not significant

\section{DISCUSSION}

Atrophic mandibular residual ridge is a highly challenging condition and has always sparked controversy among clinicians. In the light of the current trend towards less invasive approaches, short dental implants were introduced as a salvation from the aggressive surgical procedures for severely resorbed ridges. However, there is no sufficient data on their use to retain mandibular overdenture and there is no strong evidence to suggest the minimal number of short dental implants required to retain a mandibular overdenture.

The current clinical study investigated two-short implants retained mandibular overdenture as potential alternative to other high-risk treatment options. Short 
Zayed et al.

dental implants were placed by minimally invasive flapless fully guided surgical approach. Guided digital implant surgery permits implants to be placed in a prosthetic and biologically driven manner into sufficient hard and soft tissue while evading prosthetic complications and compromised aesthetics, as there is an improved control over the implant axis in relation to the position of the prosthetic tooth. Consequently, it brings about a more predictable prosthetic outcome. The pre-surgical 3D implant plan can be transferred to the patient in a more accurate and safe manner, so that implants can be placed in the correct prosthetic positions whilst evading the injury of the vital anatomic structures (30-32).

Besides, operating with a minimally invasive technique -precluding flap elevation, results in facilitated surgical procedure with shorter surgical intervention time. Thus, less post-operative sequalae and patient morbidity, in addition to preserving the soft tissue architecture, as well as maintaining the periosteum intact on buccal and lingual aspect of the alveolar ridge and the supra-periosteal plexus is kept intact and therefore, preserving the osteogenic potential and blood supply to the underlying bone and implant which, in turn, reduces the possibility of bone resorption. Moreover, it may enhance the formation of a biologic seal between the soft tissues and the implantabutment interface, as it evades the need for flap reflection and suturing $(33,34)$.

Additionally, to accelerate the osteointegration and the healing process the present study employed PBM, as there is a compelling scientific evidence sufficient to prove its significance in proliferation and differentiation of osteoblasts, bone healing and revitalization (15, 35-40), induction mitosis in cultured cells, collagen production, as well as it can boost cellular processes such as synthetization of ATP and synthesis of DNA and RNA $(41,42)$.

In this study PBM was performed using diode laser $660+5 \mathrm{~nm}$, since PBM in a range of $600-1100 \mathrm{~nm}$ (optical window) results in a deeper tissue penetration and consequently, induces a broader cell-light response (43). The dose-dependent effects of PBM are described by Arndt- Schultz's curve (42). It suggests that, weak stimulus will excite biological activity, moderate stimulus favour it, strong stimulus may halt increased activity, and excessively strong stimulus will retard or stop the biological activity. Meaning that the usage of insufficient dose has no biological effect, but if excessive energy is used a bio-suppressive effect will happen. Fluence within the range of $1-10 \mathrm{~J} / \mathrm{cm} 2$ is best to achieve an optimum biological response $(42,43)$. There's no standardized protocol for its use to promote dental implants' healing. Thus, the study also compared the effect of two different doses of PBM. The manufacturer recommended dose of: $2.4 \mathrm{~J} / \mathrm{cm} 2$ was used for group A and the other tested dose $4.8 \mathrm{~J} / \mathrm{cm} 2$ was utilized for group B. Split mouth study design was adopted because PBM has been shown to evoke a systemic effect in distant areas (44-46). The frequency of sessions every 48 hours was determined based on the literature as PBM has been shown to have a positive effect on the initial stages of implant osseointegration $(14,47,48)$.
Two Short Implant Retained Mandibular Overdenture and PBM

The main findings of this study were that after 6 months of prosthetic loading the two-implant retained mandibular overdentures revealed no biological nor mechanical complications. A minor but significant increase $(\mathrm{P}<0.05)$ was observed in the PIPD in both groups after six months but within the accepted values of healthy peri-implant tissues (49).

The modified gingival index values were very low and revealed no inflammation nor edema. The radiographic evaluation displayed a minimal insignificant marginal bone loss $(\mathrm{P}>0.05)$ from the reference line; $0.51+30,0.38+28$ for group A and group B respectively. The ISQ also, revealed insignificant changes from the baseline (at time of surgery) till six months after loading and between both groups. Group A values were almost maintained and there was a slight increase in group B values after 6 months of loading. In all the parameters measured, there was no significant differences between group A and group B. Nevertheless, insignificantly improved results were reported with Group B. this may be attributed to the possibility of more effective dose reached the target tissue, considering the amount of energy reflected by the off-contact mode of application.

In this study, we report merits of using a $660 \mathrm{~nm}$ diode laser post-surgically, which related to maintaining and/or improving secondary implant stability. In the red to the near-infrared spectrum $(600-1500 \mathrm{~nm})$, light scattering is more prevalent, and absorption has less impact. Red laser has lower penetration depth in comparison to the infrared one (50). Yet, for the wavelength employed in the present study $(660 \mathrm{~nm})$ the minimum penetration depth is roughly $3 \mathrm{~mm}$ (51). Therefore, because of the less penetration depth of the red laser we suggest using energy close to the maximum dose specified by Arndt-Schultz's curve but less than $10 \mathrm{~J} / \mathrm{cm} 2$.

To our knowledge, this is the first study that has investigated the outcome of two short implants retained mandibular overdenture placed with fully guided protocol and irradiated with PBM. Thus, direct comparison of the results of this study with those of other studies is not valid since no similar prospective studies have yet been published. Moreover, published studies which applied PBM clinically, displayed a wide diversity this may be due to the variety in the parameters used; energy density, number of applications, wavelength, and power. furthermore, in many studies the parameters used were not reported at all or inaccurately reported and dose used ranged from 6.2 to $92.1 \mathrm{~J} / \mathrm{cm} 2$ reflecting an absence of uniformity in the ideal dose for LLLT on dental implants. Additionally, it is imperative to consider the biphasic dose response as well as the inherent heterogeneity among patients, when interpreting the findings. Thus, meaningful comparison with other studies is invalid.

Although the present study included a relatively small number of patients, well-defined eligibility criteria of patients were given vigilant attention. A strict PBM protocol was followed to boost the design of the trial, the same implants (brand, surface, length, and diameter) were used for each participant, the same edentulous region was selected and the same study population. It is worth noting, that results of the current study are limited to the specific methodology, and outcomes may vary in different bone 
Zayed et al.

conditions and implants when using other PBM protocols and methodologies as well as in different follow-ups. Therefore, to establish a long-term clinical success with the proposed method, further randomized-controlled clinical trials in long-term and larger sample size are required to support the results of our study.

\section{CONCLUSIONS}

Within the limitations of this study, it can be concluded that two short implant retained overdenture can be a viable treatment option for severely resorbed mandibular ridges and PBM dose of $4.8 \mathrm{~J} / \mathrm{cm}^{2}$ has a potential positive influence on the healing and osseointegration of dental implants.

CONFLICT OF INTERESTS: The authors declare that they have no conflicts of interest.

\section{REFERENCES}

1. Bilhan H, Erdogan O, Ergin S, Celik M, Ates G, Geckili O. Complication rates and patient satisfaction with removable dentures. J Adv Prosthodont. 2012; 4:109-15.

2. Meijer HJ, Raghoebar GM, Batenburg RH, Visser A, Vissink A. Mandibular overdentures supported by two or four endosseous implants: a 10-year clinical trial. Clin Oral Implants Res. 2009;20 :722-8.

3. De Marchi RJ, Hugo FN, Padilha DM, Hilgert JB, Machado DB, Durgante PC, et al. Edentulism, use of dentures and consumption of fruit and vegetables in south Brazilian community-dwelling elderly. J Oral Rehabil. $2011 ; 38$ :533-40.

4. Doundoulakis JH, Eckert SE, Lidnquist CC, Jeffcoat MK. The implant-supported overdenture as an alternative to the complete mandibular denture. J Am Dent Assoc. 2003; 134:1455-8.

5. Van der Bilt A, Burgers M, van Kampen FM, Cune MS. Mandibular implant-supported overdentures and oral function. Clin Oral Implants Res. 2010 ;21:1209-13.

6. Dene L. Implant Supported Overdenture for the Atrophic Mandible. N Y State Dent J. 2010; 76:26-9.

7. Annibali S, Cristalli MP, Dell'Aquila D, Bignozzi I, La Monaca G, Pilloni A. Short dental implants: a systematic review. J Dent Res. 2012; 91:25-32.

8. Pommer B, Busenlechner D, Fürhauser R, Watzek G, Mailath-Pokorny G, Haas R. Trends in techniques to avoid bone augmentation surgery: Application of short implants, narrow-diameter implants and guided surgery. J Cranio maxillofac Surg. 2016; 44:1630-4.

9. Deporter D, Todescan R, Caudry S. Simplifying management of the posterior maxilla using short, porous-surfaced dental implants. Int J Perio Rest Dent. 2000; 20:476-85.

10. Atieh MA, Zadeh H, Stanford CM, Cooper LF. Survival of short dental implants for treatment of posterior partial edentulism: a systematic review. Int J Oral Maxillofac Implants. 2012; 27:1323- 31.

11. D'haese J, Ackhurst J, Wismeijer D, De Bruyn H, Tahmaseb A. Current state of the art of computerguided implant surgery. Periodontol 2000. 2017; 73:121-33.

12. Hämmerle $\mathrm{CH}$, Stone $\mathrm{P}$, Jung RE, Kapos T, Brodala N. Consensus statements and recommended clinical procedures regarding computer-assisted implant
Two Short Implant Retained Mandibular Overdenture and PBM dentistry. Int J Oral Maxillofac Implants. 2009;24 :12631.

13. Valente F, Schiroli G, Sbrenna A. Accuracy of Computer-Aided Oral Implant Surgery: A Clinical and Radiographic Study”. Int J Oral Maxillofac Implants. 2009; 24:234-42.

14. Bölükbaşı Ateş G, Ak Can A, Gülsoy M. Investigation of photobiomodulation potentiality by 635 and $809 \mathrm{~nm}$ lasers on human osteoblasts. Lasers Med Sci. 2017; 32:591-9.

15. Khalil NM, Noureldin MG. Comparison of Single Versus Multiple Low-Level Laser Applications on Bone Formation in Extraction Socket Healing in Rabbits (Histologic and Histomorphometric Study). J Oral Maxillofac Surg. 2019; 77:1760-8.

16. Ebrahimi T, Moslemi N, Rokn A, Heidari M, Nokhbatolfoghahaie H, Fekrazad R. The influence of low-intensity laser therapy on bone healing. J Dent. 2012; 9:238-48.

17. Khadra M, Kasem N, Haanaes HR, Ellingsen JE, Lyngstadaas SP. Enhancement of bone formation in rat calvarial bone defects using low-level laser therapy. Oral Surg Oral Med Oral Pathol Oral Radiol Endod. 2004; 97:693-700.

18. Arany PR. Craniofacial Wound Healing with Photobiomodulation Therapy: New Insights and Current Challenges. J Dent Res. 2016; 95:977-84.

19. Mayer L, Gomes FV, Carlsson L, Gerhardt-Oliveira M. Histologic and Resonance Frequency Analysis of PeriImplant Bone Healing After Low-Level Laser Therapy: An in-Vivo Study. Int J Oral Maxillofac Implants. 2015; 30:1028-35.

20. Tang E, Arany P. Photobiomodulation and implants: implications for dentistry. J Periodontal Implant Sci. 2013; 43:262-8.

21. DE Vico G, Ferraris F, Arcuri L, Guzzo F, Spinelli D. a novel workflow for computer guided implant surgery matchingdigital dental casts and CBCT scan. Oral Implantol (Rome). 2016 ;9:33-48.

22. Gutierrez JL, Bagan JV, Bascones A, Lamas R, Llena J. Morales A, et al. Consensus document on the use of antibiotic prophlaxis in dental surgery and procedures. Med oral pathol oral cir buccal. 2006; 11:188-205.

23. Borrajo JL, Varela LG, Castro GL, Rodriguez-Nunez, Figueroa MG, Torreira MG Efficacy of chlorhexidine mouth rinses with and without alcohol: clinical study. J Periodont. 2002; 73:317-21.

24. Myung-Sun K, Yong-Ick C, Min-Suk K, Sang-Chul J, Young HH. Effect of $660 \mathrm{~nm}$ Light-Emitting Diode on the Wound Healing in Fibroblast-Like Cell Lines. Inter J Photoenergy. 2015; 2015:1-9.

25. Bragger U, Burgin WB, Hammerle $\mathrm{CH}$, Lang NP. Associations between clinical parameters assessed around implants and teeth. Clin Oral Implants Res. 1997; 8:412-21.

26. Mombelli A, van Oosten MA, Schurch E, Land NP. The microbiota associated with successful or failing osseointegrated titanium implants. Oral Microbiol Immunol. 1987; 2:145-51.

27. Sim CP, Lang NP. Factors influencing resonance frequency analysis assessed by osstel mentor during implant tissue integration: I. instrument positioning 
Zayed et al.

bone structure, implant length. Clin Oral Implants Res. 2010; 21:598-604.

28. Herrero-Climent M, Santos-García R, Jaramillo-Santos R, Romero-Ruiz MM, Fernández-Palacin A, LázaroCalvo P, Bullón P, Ríos-Santos JV. Assessment of Osstell ISQ's reliability for implant stability measurement: A cross-sectional clinical study. Med Oral Patol Oral Cir Bucal. 2013;18: 877-82.

29. De Bruyn H, Vandeweghe S, Ruyffelaert C, Cosyn J, Sennerby L. Radiographic evaluation of modern oral implants with emphasis on crestal bone level and relevance to peri-implant health. Periodontol 2013; 62:256-70.

30. Cassetta M, Stefanelli LV, Giansanti M, Calasso S. Accuracy of implant placement with a stereolithographic surgical template. Int $\mathrm{J}$ Oral Maxillofac Implants. 2012; 27:655-63.

31. Pozzi A, Tallarico M, Marchetti M, Scarfò B, Esposito M. Computer-guided versus free-hand placement of immediately loaded dental implants: 1-year postloading results of a multicentre randomised controlled trial. Eur J Oral Implantol. 2014; 7:229-42.

32. Jacobs R, Quirynen M, Bornstein MM. Neurovascular disturbances after implant surgery. Periodontol 2000. 2014; 66:188-202.

33. Casap N, Tarazi E, Wexler A, Sonnenfeld U, Lustmann J. Intraoperative computerized navigation for flapless implant surgery and immediate loading in the edentulous mandible. Int $\mathrm{J}$ Oral Maxillofac Implants. 2005; 20:92-8.

34. Hahn J. Single-stage, immediate loading, and flapless surgery. J Oral Implantol. 2000; 26:193-8.

35. Torkzaban P, Kasraei S, Torabi S, Farhadian M. Low level laser therapy with $940 \mathrm{~nm}$ diode laser on stability of dental implants: a randomized controlled clinical trial. Lasers Med Sci. 2018; 33:287-93.

36. Amid R, Kadkhodazadeh M, Ahsaie MG, Hakakzadeh A. Effect of low-level laser therapy on proliferation and differentiation of the cells contributing in bone regeneration. J Lasers Med Sci. 2014; 5:163-70.

37. Barbosa D, de Souza RA, Xavier M, da Silva FF, Arisawa EA, Villaverde AG. Effects of low-level laser herapy (LLLT) on bone repair in rats: optical densitometry analysis. Lasers Med Sci. 2013; 28:65156.

38. Stein A, Benayahu D, Maltz L, Oron U. Low-level laser irradiation promotes proliferation and differentiation of human osteoblasts in vitro. Photomed Laser Surg. 2005; 23:161-6.

39. Gomes FV, Mayer L, Massotti FP, Baraldi CE, Ponzoni D, Webber JB, de Oliveira MG. Low-level laser therapy improves peri-implant bone formation: resonance frequency, electron microscopy, and stereology findings in a rabbit model. Int $\mathrm{J}$ Oral Maxillofac Surg. 2015; 44:245-51.

40. Aoki A, Mizutani K, Schwarz F, Sculean A, Yukna RA, Takasaki AA, Romanos GE, et al. Periodontal and periimplant wound healing following laser therapy. Periodontol 2000. 2015; 68:217-69.

41. AlGhamdi KM, Kumar A, Moussa NA Low-level laser therapy: a useful technique for enhancing the
Two Short Implant Retained Mandibular Overdenture and PBM proliferation of various cultured cells. Lasers Med Sci. 2012; 27:237-49.

42. Pires Oliveira DA, de Oliveira RF, Zangaro RA, Soares CP. P. Soares. Evaluation of low-level laser therapy of osteoblastic cells. Photomed Laser Surg. 2008; 26:4014.

43. Raghavendra S, Wood MC, Taylor TD. Early wound healing around endosseous implants: a review of the literature. Int J Oral Maxillofac Implants. 2005; 20:425-31.

44. Hopkins JT, McLoda TA, Seegmiller JG, David Baxter G. Low-level laser therapy facilitates superficial wound healing in humans: a triple-blind, sham-controlled study. J.Athletic Training. 2004;39: 223-9.

45. Byrnes KR, Waynant RW, Ilev IK, Wu X, Barna L, Smith K, Heckert R, Gerst $\mathrm{H}$ et al. Light promotes regeneration and functional recovery and alters the immune response after spinal cord injury. Lasers Surg Med. 2005; 36:171-85.

46. Weber JB. Effect of Three Different Protocols of LowLevel Laser Therapy on Thyroid Hormone Production After Dental Implant Placement in an Experimental Rabbit Model. Photomedicine and Laser Surgery. 2014; 32:11-8.

47. Pinheiro AL, Gerbi ME. Photoengineering of bone repair processes. Photomed Laser Surg. 2006; 24:16978.

48. Bloise N, Ceccarelli G, Minzioni P, Vercellino M, Benedetti L, De Angelis MG, Imbriani M, Visai L. Investigation of low-level laser therapy potentiality on proliferation and differentiation of human osteoblastlike cells in the absence/presence of osteogenic factors. J Biomed Opt. 2013; 18:1-14.

49. Renvert S, Persson GR, Pirih FQ, Camargo PM. Periimplant health, peri-implant mucositis, and periimplantitis: Case definitions and diagnostic considerations. J Periodontol. 2018 ;89 :304-12.

50. Matys J, Grzech-Le'sniak K, Flieger R, Dominiak M. Assessment of an impact of a diode laser mode with wavelength of $980 \mathrm{~nm}$ on a temperature rise measured by means of k-02 thermocouple: preliminary results. Dent Med Problems. 2016; 53: 345-51.

51. Niemz MH. Laser-Tissue Interactions - Fundamentals and Applications. $3^{\text {rd }}$ ed. Berlin, Germany: Springer; 2004. 